\title{
AT-101 $(R-(-)$-Gossypol Acetic Acid) Enhances the Effectiveness of Androgen Deprivation Therapy in the VCaP Prostate Cancer Model
}

\author{
Natalie McGregor, ${ }^{1}$ Lalit Patel, ${ }^{1}$ Matthew Craig, ${ }^{1}$ Savannah Weidner, ${ }^{1}$ Shaomeng Wang, ${ }^{1,2}$ \\ and Kenneth J. Pienta ${ }^{1,2,3,4 *}$ \\ ${ }^{1}$ Department of Internal Medicine, University of Michigan School of Medicine, Ann Arbor, Michigan \\ ${ }^{2}$ University of Michigan Comprehensive Cancer Center, Ann Arbor, Michigan \\ ${ }^{3}$ Department of Urology, University of Michigan School of Medicine, Ann Arbor, Michigan \\ ${ }^{4}$ Michigan Center for Translational Pathology, Ann Arbor, Michigan
}

\begin{abstract}
Prostate cancer remains a leading cause of cancer death in American men. Androgen deprivation therapy (ADT) is the most common treatment for advanced prostate cancer patients; however, ADT fails in nearly all cases resulting in castration resistant or androgen-insensitive (AI) disease. In many cases, this progression results from dysregulation of the pro-survival Bcl-2 family proteins. Inhibition of pro-survival Bcl-2 family proteins, therefore, may be an effective strategy to delay the onset of AI disease. Gossypol, a small molecule inhibitor of pro-survival Bcl-2 family proteins, has been demonstrated to inhibit AI prostate cancer growth. The apoptotic effect of gossypol, however, has been demonstrated to be attenuated by the presence of androgen in a prostate cancer xenograft mouse model (Vertebral Cancer of Prostate [VCaP]) treated with AT-101 (R-(-)-gossypol acetic acid). This study was undertaken to better understand the in vitro effects of androgen receptor (AR) on AT-101-induced apoptosis. VCaP cells treated with AT-101 demonstrated an increase in apoptosis and downregulation of Bcl-2 prosurvival proteins. Upon AR activation in combination with AT-101 treatment, apoptosis is reduced, cell survival increases, and caspase activation is attenuated. Akt and X inhibitor of apoptosis (XIAP) are downregulated in the presence of AT-101, and AR stimulation rescues protein expression. Combination treatment of bicalutamide and AT-101 increases apoptosis by reducing the expression of these pro-survival proteins. These data suggest that combination therapy of AT-101 and ADT may further delay the onset of AI disease, resulting in prolonged progression-free survival of prostate cancer patients. J. Cell. Biochem. 110: 1187-1194, 2010. @ 2010 Wiley-Liss, Inc.
\end{abstract}

KEY WORDS: PROSTATE CANCER; GOSSYPOL; APOPTOSIS; BCL-2; ANDROGEN DEPRIVATION THERAPY

$\mathrm{P}$ rostate cancer is the second leading cause of cancer death in men, second only to lung cancer in the US. It is estimated that in 2009 prostate cancer will have accounted for 25\% of malignancies in men, with 192,280 new cases in the US. In addition, 9\% of all estimated cancer deaths of men will be due to prostate cancer in the US [Jemal et al., 2009]. Localized disease is highly curable through local therapies including radiation therapy and/or radical prostatectomy; however, $20 \%$ of men diagnosed will have a relapse of disease at metastatic sites [Fujimoto et al., 2005; Taichman et al., 2007; Walczak and Carducci, 2007].

Huggins and Hodges [1941] reported that reducing circulating testosterone levels via surgical castration resulted in a dramatic palliation of cancer symptoms and an overall improvement in quality of life [Perlmutter and Lepor, 2007]. Soon after these reports, reductions in testosterone levels through androgen deprivation therapy (ADT) became widely used as the first-line treatment for advanced prostate cancer. Unfortunately, the patients on ADT progress to castration-resistant or androgen-independent (AI) disease within 2-3 years [Pienta and Bradley, 2006; Walczak and Carducci, 2007]. The onset of this advanced state heralds a patient life expectancy of approximately 16-18 months [Pienta and Bradley, 2006].

Androgens are important regulators of growth and differentiation in the prostate gland [Miyamoto et al., 2004; Perlmutter and Lepor,

Grant sponsor: NCI Grant U-19; Grant number: CA113317; Grant sponsor: NIH SPORE in Prostate Cancer Grant P50; Grant number: CA46592.

*Correspondence to: Kenneth J. Pienta, MD, 1500 E. Medical Center Drive, 7303 Cancer Center, Ann Arbor, MI 481095946. E-mail: kpienta@umich.edu

Received 25 March 2010; Accepted 29 March 2010 • DOI 10.1002/jcb.22633 • ( 2010 Wiley-Liss, Inc.

Published online 29 June 2010 in Wiley InterScience (www.interscience.wiley.com). 
2007]. Primary prostate cancer tumors rarely contain androgen receptor $(\mathrm{AR})$ mutations or alterations in gene abundance; however, the frequency of AR mutations is much higher in metastases, occurring in 21-44\% of tumors. Although amplifications of AR are seen in $20-30 \%$ of AI tumors, few mutations observed render the gene product unable to function as a transcriptional activator. Thus, deregulation of AR rather than the loss of function is more often responsible for prostate cancer progression. Alterations in AR in conjunction with changes in the function of pathways controlling apoptosis, survival, and proliferation are associated with progression to aggressive and incurable castration resistant prostate cancer [Eder et al., 2001; Heinlein and Chang, 2004].

In 1984 a chromosome translocation found in a cell line derived from the peripheral blood of a B-cell leukemia patient was describe. Within this translocation a gene was found and termed Bcl-2 [Pegoraro et al., 1984]. Shortly thereafter, it was determined that Bcl-2 did not function like other known oncogenes. Instead, the gene product protected the cell from apoptosis and displayed no effect on proliferation [Tsujimoto et al., 1984; Hockenbery et al., 1990]. Advances in bioinformatics and the completion of the human genome project have lead to the discovery of at least 25 genes with homology to Bcl-2. These genes are part of the Bcl-2 family, and all of them are involved in the regulation of mitochondrial or intrinsic apoptosis [Marzo and Naval, 2008]. Members of the Bcl-2 family contribute to the regulation of apoptosis in several ways and are broken up into two main groups: pro-survival and pro-apoptotic. Bcl-2 family members may contain up to four Bcl-2 homology domains (BH) domains. The $\mathrm{BH}$ domains are part of a highly conserved hydrophobic groove in the proteins formed by alpha helices in Bcl-2 family members containing 3-4 BH domains. The $\mathrm{BH}$ domains serve as binding sites for Bcl-2 family members to interact with each other [Petros et al., 2004]. Prosurvival Bcl-2 family members include Bcl-2, Bcl-xL, Bcl-w, and Mcl1 ; its members contain all four BH domains. In contrast, the proapoptotic Bcl-2 family members can be divided into two groups based on BH domains: Bcl-2 effectors, which contain BH domains 1-3, and BH3 only proteins that contain only the BH3 domain [Cory and Adams, 2002; Chipuk and Green, 2008]. The pro-survival proteins also contain a carboxy-terminal transmembrane domain for localization to the outer mitochondrial membrane. Only $\mathrm{Bcl}-2$ is targeted to the mitochondrial membrane at all times while $\mathrm{Bcl}-\mathrm{xL}$, $\mathrm{Bcl}-\mathrm{w}$, and $\mathrm{Mcl}-1$ are normally present in the cytosol and only translocate to the mitochondria in response to an apoptotic stimulus [Youle and Strasser, 2008]. The exact mechanism of apoptosis induction by Bcl-2 family member effector proteins remains unclear and is a controversial topic. Many demonstrate Bcl-2 overexpression, resulting in enhanced tumorigenesis and chemotherapy resistance [Frenzel et al., 2009]. It has also been shown that Bcl-2 levels rise during the progression from androgen-sensitive to androgeninsensitive prostate cancer in human xenograft murine models [Loberg et al., 2006]. Importantly, Bcl-2 is overexpressed in approximately two-thirds of castration-resistant prostate cancers [Ma and Adjei, 2009].

Cancer cells overcome many obstacles to promote disease progression including leaving primary sites, overcoming reductions in growth factors and hormones, and developing resistance to chemotherapeutics. Pro-survival Bcl-2 family members play a role in each of these events. Overexpression of $\mathrm{Bcl}-2$ is commonly found in chemotherapy-resistant tumors and castration-resistant prostate cancer. Several drugs targeting Bcl-2 are in clinical trials, including antisense RNA therapy and BH-3 mimetics [Huang et al., 2007].

The BH-3 mimetic AT-101 (R-(-)-gossypol acetic acid), is a natural compound found in cotton seed oil that induces apoptosis by inhibition of pro-survival Bcl-2 family members. It has been used effectively against several androgen-sensitive and -insensitive prostate cancer cell lines, bladder cancer cell lines, and multiple myeloma cells [Huang et al., 2007; Loberg et al., 2007; Zhang et al., 2007; Kline et al., 2008; Macoska et al., 2008; Meng et al., 2008]. AT101 was recently studied using the VCaP prostate cancer cell line, which possess a wild-type AR [van Bokhoven et al., 2003; Loberg et al., 2007]. In murine VCaP xenografts, a combination of AT-101 treatment and castration had a synergistic effect, reducing tumor burden and delaying the onset of androgen-independent disease. However, mice receiving single AT-101 or androgen deprivation as monotherapies demonstrated less significant reduction in tumor burden [Macoska et al., 2008]. These data suggest that androgen can attenuate AT-101-induced apoptosis resulting in increased cancer cell survival and progression. This study was undertaken to determine the mechanism by which androgens attenuate AT-101-induced apoptosis and to identify potential therapeutic targets involved.

\section{MATERIALS AND METHODS}

\section{MATERIALS}

AT-101 ( $R$-(-)-gossypol acetic acid) was provided by Ascenta Therapeutics, Inc. (San Diego, CA), bicalutamide (Casodex) was purchased from Astra Zeneca (Wilmington, DE), $5 \alpha$-dihydrotestosterone (DHT) was purchased from Sigma-Aldrich (Saint Louis, M0). Cell Death Detection ELISA was purchased from Roche (Basel, Switzerland). ACEA-ces real-time cell analysis system was purchased from ACEA Biosciences, Inc. (San Diego, CA). Antibodies were purchased from Cell Signaling Technology (Boston, MA).

\section{CELL CULTURE}

Prostate cancer vertebral cancer of prostate (VCaP) cells were isolated from a vertebral metastatic lesion [Korenchuk et al., 2001]. Cells were maintained in DMEM (Invitrogen, Carlsbad, CA) supplemented with 10\% FBS and 1\% antibiotic/antimycotic and were incubated at $37^{\circ} \mathrm{C}$ and with a $5 \% \mathrm{CO}_{2}$ atmosphere. Cells were passaged using 0.25\% trypsin-EDTA (Invitrogen). For treatment, androgen-depleted media were used. Phenol red free DMEM and charcoal-stripped FBS were purchased from Invitrogen. Phenol red free DMEM was supplemented with 10\% charcoal-stripped FBS and $1 \%$ antibiotic/antimycotic.

\section{TREATMENT PREPARATION}

AT-101 was dissolved in DMSO at $5 \mathrm{mg} / \mathrm{ml}$ and stored at $-20^{\circ} \mathrm{C}$. Bicalutamide pills were crushed with a mortar and pestle and then dissolved in DMSO at $10 \mathrm{mg} / \mathrm{ml}$ and stored at $-20^{\circ} \mathrm{C}$. DHT was dissolved in ethyl alcohol at a concentration of $1 \mathrm{mg} / \mathrm{ml}$, DHT was prepared and used immediately for treatment. Final concentrations of vehicle DMSO and ethyl alcohol did not exceed $0.2 \%$ and $0.001 \%$, respectively. 


\section{CELL DEATH DETECTION ELISA}

VCaP cells were seeded at a density of $5 \times 10^{4}$ cells/well in a 96-well plate with complete DMEM. The plates were incubated for $24 \mathrm{~h}$ prior to treatment and incubated for $48 \mathrm{~h}$ after treatment. Cells were lysed after the $48 \mathrm{~h}$ treatment and assayed for apoptosis using the Cell Death Detection ELISA (Roche) following the manufacturer's supplied protocol.

\section{REAL-TIME CELL PROLIFERATION ASSAY}

VCaP cells were seeded at a density of $5 \times 10^{4}$ cells/well in androgen-depleted DMEM. The plate was then inserted into the ACEA RT-CES system which measures the electrical impedance created by each cell every $15 \mathrm{~min}$ and calculates a cell index value for each well (ACEA Biosciences, Inc.). Cells were monitored for $24 \mathrm{~h}$ prior to treatment. The plate was then removed, each was well treated, and the plate was then replaced back into the ACEA RT-CES. Data were collected for an additional $96 \mathrm{~h}$.

\section{WESTERN BLOT}

VCaP cells were plated and placed in androgen-depleted DMEM for $24 \mathrm{~h}$, treated as specified, and incubated for an additional $48 \mathrm{~h}$. The cells were then lysed in Cell Lysis Buffer (Cell Signaling Technology) and $2 \times$ Pierce Halt protease inhibitor cocktail and Halt phosphatase inhibitor cocktail (Thermo Fisher Scientific, Rockford, IL). Protein concentrations were determined using Bradford reagent from BioRad (Hercules, CA), and $30 \mu \mathrm{g}$ total protein was loaded into each well. Lysates were resolved using sodium dodecyl sulfatepolyacrylamide gel electrophoresis with 4-20\% Tris-glycine gels (Invitrogen) and then transferred to polyvinylidene difluoride membrane (Millipore, Billerica, MA). Membranes were blocked using 5\% milk in TBS $+0.1 \%$ Tween for $1 \mathrm{~h}$ at room temperature. The membranes were then incubated in primary antibody in 5\% milk either overnight at $4{ }^{\circ} \mathrm{C}$, or for $60 \mathrm{~min}$ at room temperature. They were then washed three times in TBS $+0.1 \%$ Tween-20 and incubated for $60 \mathrm{~min}$ in HRP-conjugated secondary antibody. Presence of the proteins was determined by using Immobilon Western Chemiluminescent HRP Substrate (Millipore). Images were scanned and densitometry analyzed using ImageJ 1.41 (National Institutes of Health, Bethesda, MD).

\section{STATISTICAL ANALYSIS}

Graphs and statistics were generated and analyzed with GraphPad Prism software (San Diego, CA). The Student's t-test was used to compare two groups, and one-way analysis of variance with Bonferroni post hoc tests used to compare multiple groups. $P$-values less than 0.05 were considered statistically significant.

\section{RESULTS}

\section{ANDROGEN RECEPTOR ACTIVATION RESCUES CELLULAR PROLIFERATION IN VCAP CELLS TREATED WITH AT-101}

In order to determine the effects of AR activation on AT-101-treated VCaP cells, cellular proliferation was assessed using the ACEA RTCES system. VCaP cells were plated in duplicate and treated for $48 \mathrm{~h}$ in androgen-depleted DMEM with the following treatments: vehicle control, $5 \mu \mathrm{M}$ AT-101, $10 \mathrm{~nm}$ DHT, and a combination treatment of
$5 \mu \mathrm{m}$ AT-101 and $10 \mathrm{nM}$ DHT. Treatment of AT-101 in androgendepleted media resulted in a decrease in proliferation or viability as compared to control cells. Stimulation with DHT rescued proliferation in AT-101-treated VCaP cells (Fig. 1A). These results suggest that AR activation can partially restore cellular proliferation in AT101-treated VCaP cells.

\section{ANDROGEN RECEPTOR ACTIVATION ATTENUATES AT-101-INDUCED APOPTOSIS}

Next, the effect of AR activation on apoptosis in AT-101-treated VCaP cells was determined by Cell Death Detection ELISA (Fig. 1B). AT-101-treated VCaP cells demonstrated elevated apoptosis as compared to untreated controls. Consistent with the cellular proliferation analysis and findings previously reported [Loberg et al., 2007] stimulation with $10 \mathrm{~nm}$ DHT significantly attenuated AT-101-induced apoptosis. Apoptotic signaling was also examined by immunoblot analysis of caspase and poly(ADP-ribose) polymerase (PARP) cleavage. Caspase activation and PARP cleavage are induced by AT-101 treatment. AR activation inhibited cleavage of caspase 7, caspase 9, and PARP. Interestingly, caspase 3 cleavage is only reduced in cells treated with the AT-101 and DHT combination.

\section{AT-101 DECREASES THE EXPRESSION OF BCL-2, BCL-XL, AND AKT: ANDROGEN RECEPTOR ACTIVATION RECOVERS EXPRESSION OF THESE PRO-SURVIVAL PROTEINS}

VCaP cells were treated with AT-101 and DHT. The expression of Bcl-2 and Bcl-xL was analyzed by immunoblot analysis (Fig. 2). AT-101 reduces the expression of pro-survival proteins Bcl-2 and Bcl-xL when compared to control VCaP cells. The addition of DHT has no effect on Bcl-2; however, AR activation partially rescues Bcl-xL expression. The expression of AKT, phopho-AKT ser 473, and XIAP was also examined. AKT expression is reduced with AT-101 treatment, despite a marginal increase in phospho-AKT ser473. The addition of DHT recovers some AKT expression while increasing phospho-AKT ser473. Inhibitor of apoptosis XIAP expression is slightly reduced with AT-101 treatment but remains comparable to the expression demonstrated in control and DHTtreated samples.

\section{INHIBITION OF ANDROGEN RECEPTOR ACTIVATION BY BICALUTAMIDE RECOVERS AT-101-INDUCED REDUCTION OF CELLULAR VIABILITY AND APOPTOSIS IN VCAP CELLS}

To determine the effect of AT-101 as an adjuvant to ADT cellular proliferation (Fig. 3A) and apoptosis (Fig. 3B) were examined in VCaP cells treated with the antiandrogen bicalutamide. VCaP cells treated with a combination of DHT and bicalutamide have a growth rate similar to that of control cells and are not significantly different, while DHT-treated cell growth is significantly different from all other treated samples $(P<0.01)$. Meanwhile, cells treated with DHT, bicalutamide, and AT-101 show reduced viability and similar growth kinetics to those demonstrated by AT-101-treated cells in the absence of DHT. Consistent with the cellular proliferation data, the apoptosis ELISA indicated that bicalutamide treatment alone had no effect on apoptosis. DNA fragmentation that was not significantly different in bicalutamide-treated samples as compared to control or 


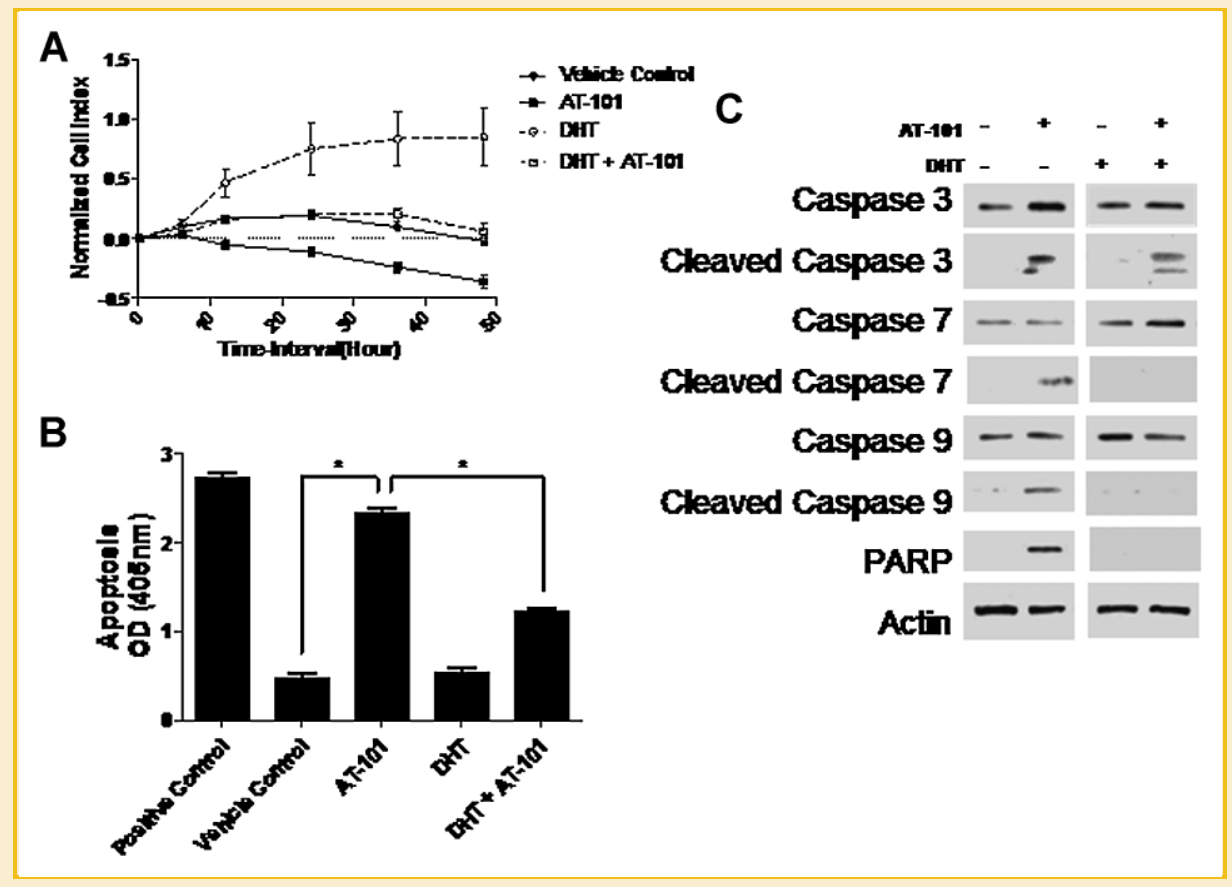

Fig. 1. A: Graphic representation of cellular proliferation of VCaP cells determined by ACEA. Cells were treated with vehicle, $5 \mu M$ AT-101, $10 \mathrm{nM}$ DHT, and a combination of $5 \mu \mathrm{M}$ AT-101 and $10 \mathrm{~nm}$ DHT; data were collected for $48 \mathrm{~h}$ in androgen-depleted media. Key time points were chosen and graphed. B: Apoptosis was analyzed by measuring DNA nucleosome fragmentation by Cell Death Detection ELISA using the same treatments for $48 \mathrm{~h}$. The data represent the mean \pm SD ( ${ }^{*} P<0.001$ ). C: Immunoblot analysis of caspase activation and PARP cleavage with vehicle, DHT, and AT-101 treatment with and without androgen receptor activation.

DHT-treated cells. However, the addition of bicalutamide to AT-101 treatment rescued cell death in the presence of androgen stimulation as compared to AT-101 treatment with DHT.

\section{BICALUTAMIDE TREATMENT IN COMBINATION WITH AT-101 ABROGATES ACTIVATED ANDROGEN RECEPTOR MEDIATED REDUCTION OF CASPASE ACTIVATION}

To confirm that apoptosis is occurring with combination treatment caspase and PARP activation were evaluated by immunoblot

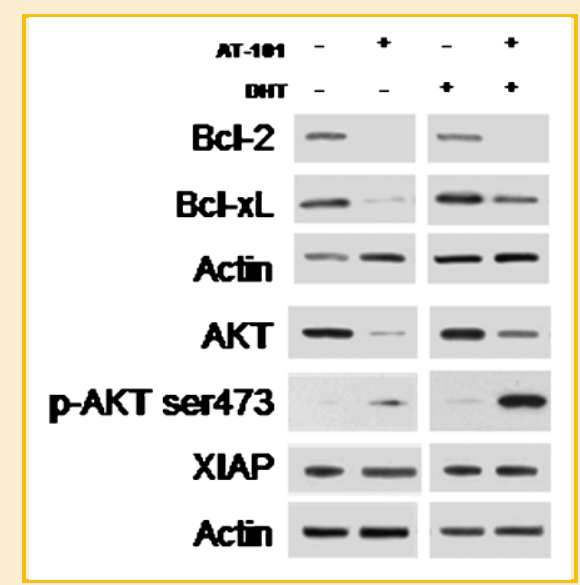

Fig. 2. Expression levels of $B c l-2, B c l-x L$, AKT, phospho-AKT ser 473, and XIAP in response to the following treatments: vehicle, $5 \mu \mathrm{M}$ AT-101 by immunoblot, $10 \mathrm{~nm}$ DHT, and a combination of $5 \mu \mathrm{M} \mathrm{AT-101}$ and $10 \mathrm{~nm}$ DHT. analysis (Fig. 4). Bicalutamide as a monotherapy is able to activate and cleave caspase 9 but is not sufficient to activate executioner caspases 3 and 7. In addition, PARP cleavage is not present in cells treated with bicalutamide monotherapy. Inhibition of AR activation by bicalutamide in combination with AT-101 abolishes the inhibition of caspases 7 and 9. Caspase 3 and PARP activation were also partially recovered. These data suggest that ADT alone will not induce apoptosis and that a combination of bicalutamide and AT-101 is necessary to induce apoptosis by the caspase cascade.

\section{UPREGULATION OF PRO-SURVIVAL PROTEINS BY ANDROGEN STIMULATION IN THE PRESENCE OF AT-101 IS PARTIALLY NEGATED BY BICALUTAMIDE TREATMENT}

The expression of pro-survival proteins was accessed by immunoblotting (Fig. 5A) and then evaluated by densitometry (Fig. 5B,C). Bicalutamide treatment increases the expression of $\mathrm{Bcl}-2$; however, the expression of Bcl-xL, AKT, phospho-AKT ser473, XIAP, and survivin do not change significantly. Combination treatment of AT101 and bicalutamide in the presence of androgen stimulation abolishes the upregulation of Bcl-xL as compared to AT-101 with androgen stimulation. In addition, AT-101 and bicalutamide treatment decreased the expression of survivin and XIAP. Survivin is only expressed in androgen-depleted media or in the presence of bicalutamide. Furthermore, survivin expression is reduced by AT101. The expression of AKT is reduced in VCaP cells receiving combination therapy; phospho-AKT ser473 expression continues to be upregulated. ADT used in combination with AT-101 is more effective than either therapy alone at reducing the expression of pro- 


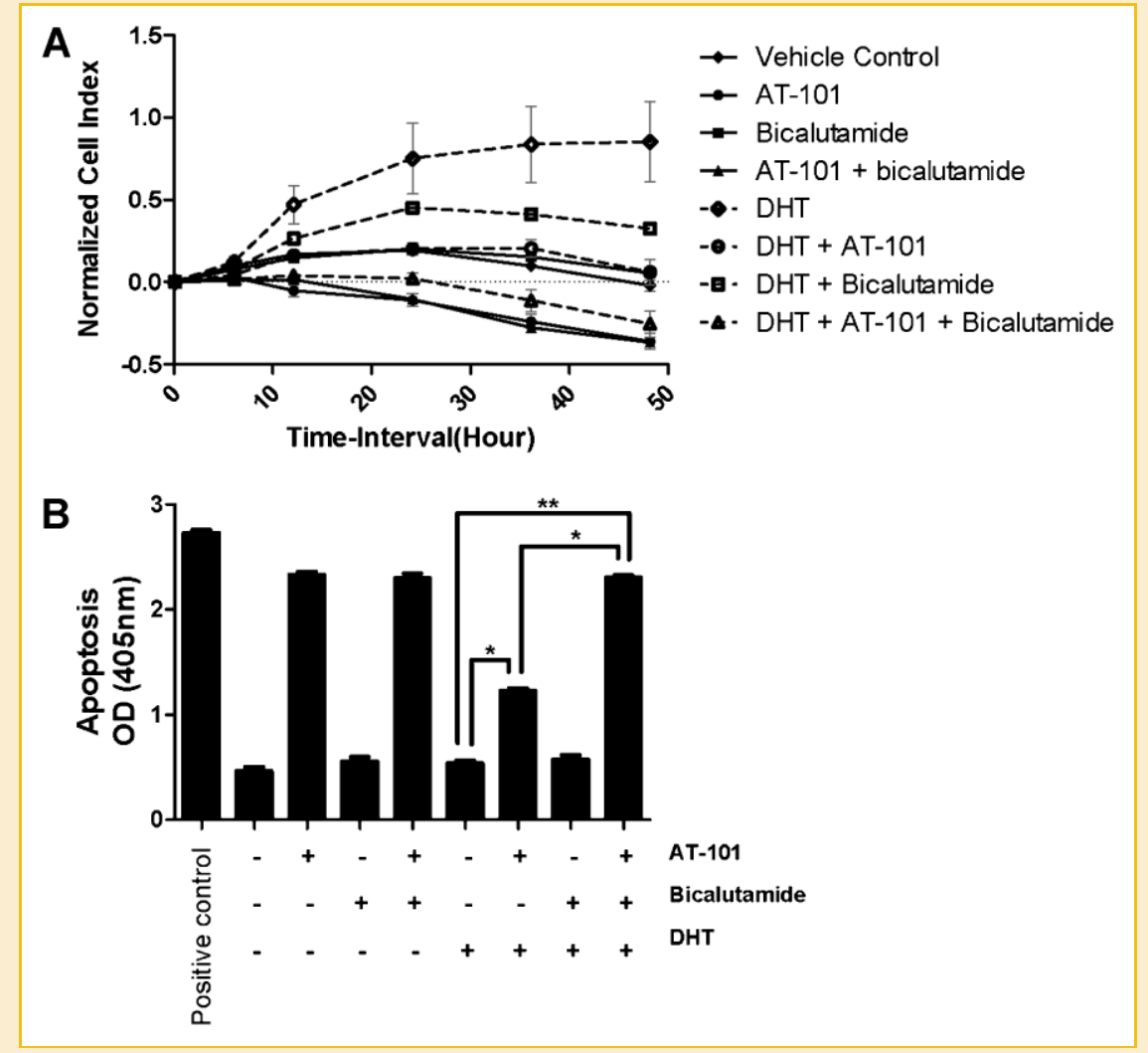

Fig. 3. A: Cellular proliferation analysis by ACEA of VCaP cells treated with vehicle control, $5 \mu M$ AT-101, $10 \mu M$ bicalutamide, combination of AT-101 and bicalutamide, $10 \mathrm{nM}$ DHT, combination of DHT and AT-101, combination of DHT and bicalutamide, and combination of AT-101, bicalutamide, and DHT in androgen-depleted media. Data were collected for $48 \mathrm{~h}$ and key time points were graphed. B: Apoptosis was examined by cell death detection ELISA, with the same treatments; data were collected at $48 \mathrm{~h}$, the data represent the mean \pm SD $\left({ }^{*} P<0.001\right)$.

survival proteins, Bcl-xL, total AKT, and XIAP, which continue to be upregulated with single treatment. Interestingly, the expression of phospho-AKT ser473 remains upregulated with combination treatment.

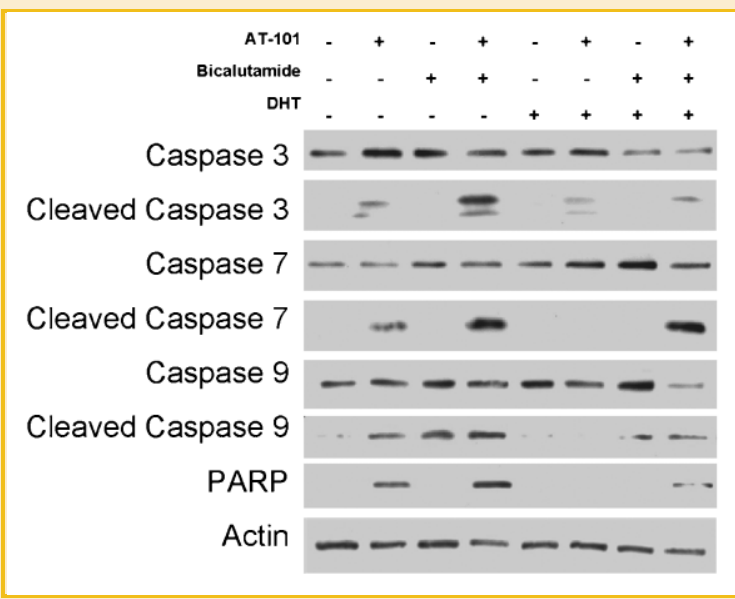

Fig. 4. Immunoblot analysis of caspase activation and PARP cleavage with the following treatments: vehicle control, $5 \mu \mathrm{M}$ AT-101, $10 \mu \mathrm{M}$ bicalutamide, combination of AT-101 and bicalutamide, $10 \mathrm{nM} \mathrm{DHT,} \mathrm{combination} \mathrm{of} \mathrm{DHT} \mathrm{and}$ AT-101, combination of DHT and bicalutamide, and combination of AT-101, bicalutamide, and DHT in androgen-depleted media for $48 \mathrm{~h}$.

\section{DISCUSSION}

ADT is the leading treatment for advanced metastatic prostate cancer in men and has been for over 60 years [Perlmutter and Lepor, 2007]. However, almost 100\% of men will have a re-emergence of disease within 3 years of starting ADT [Pienta and Bradley, 2006]. There are multiple mechanisms that lead to androgen insensitivity, including dysregulation of growth factors and deregulation of apoptotic pathways [Eder et al., 2001; Heinlein and Chang, 2004; Pienta and Bradley, 2006]. Pro-survival Bcl-2 family members play an important role in the progression to androgen refractory prostate cancer, and have been shown to be upregulated in many cancers [Loberg et al., 2006]. Several drugs designed to inhibit pro-survival Bcl-2 family members are in clinical trials, including antisense oligonucleotides and BH3 inhibitors [Huang et al., 2007]. AT-101, a small molecule BH3 mimetic extracted from cotton seed oil, is the only anticancer drug that demonstrably inhibits the suppressive functions of Bcl-2, Bcl-xL, and Mcl-1 [Wang et al., 2006]. In this study we examine the effects of AT-101 treatment in an androgenstimulated environment to better understand the molecular mechanisms by which AR activation can overcome apoptosis. In addition, we have provided a molecular rationale for therapeutic intervention using combinations of AT-101 with antiandrogen treatment. 


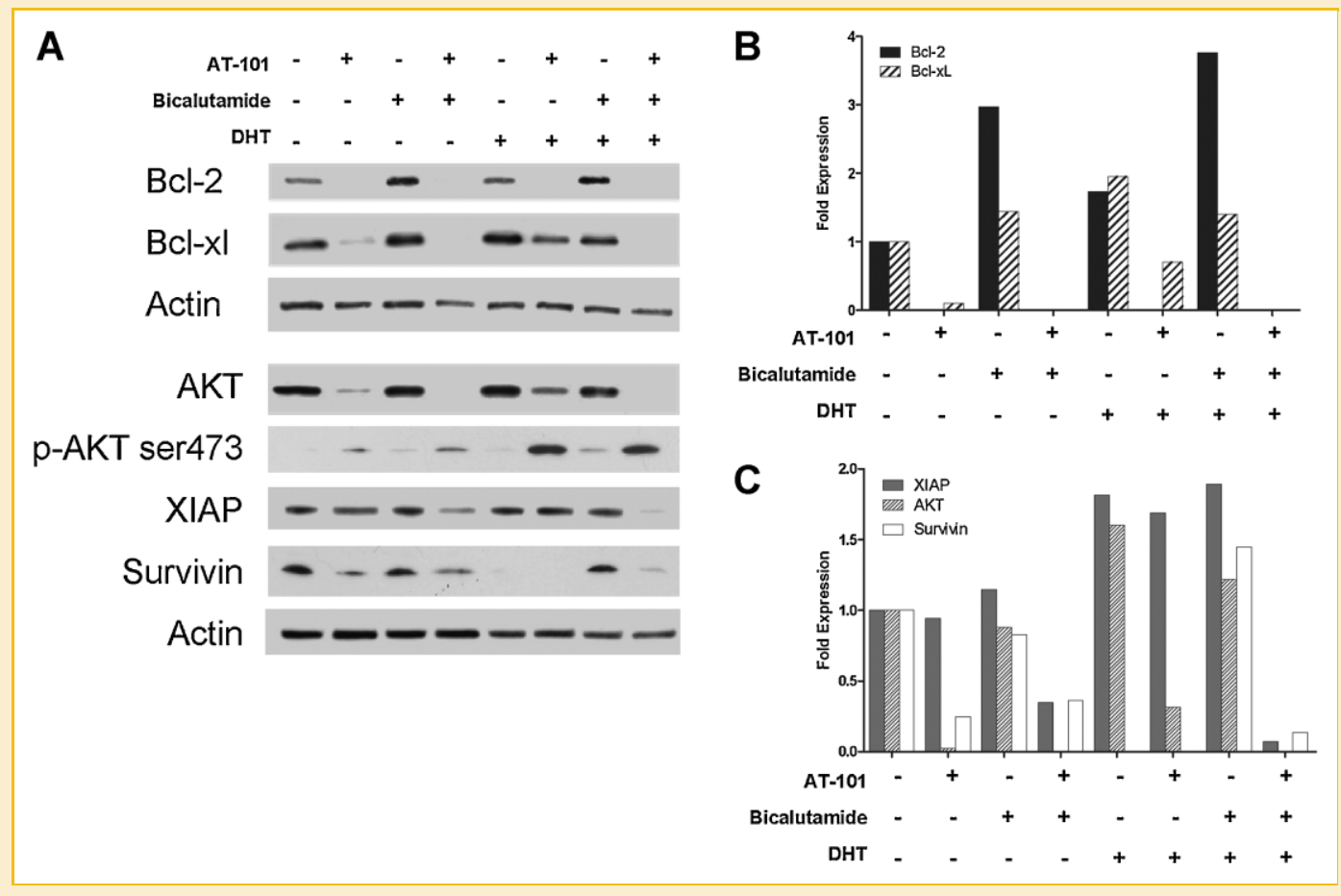

Fig. 5. A: Immunoblot analysis of the expression levels of $B c l-2, B c l-x L, A K T$, phospho-AKT ser 473, XIAP and Survivin in response to the following treatments: vehicle control, $5 \mathrm{mM}$ AT-101, 10mM bicalutamide, combination AT-101 and bicalutamide, 10nM DHT, combination DHT and AT-101, combination DHT and bicalutamide, and combination AT101, bicalutamide, and DHT in androgen depleted media for 48 hours. B: Densitometry of the immunoblots for Bcl-2 and Bcl-xL. C: Densitometry of the immunoblots of XIAP, AKT, and Survivin.

Treatment with AT-101 negatively regulates pro-survival Bcl-2 family proteins (Fig. 2). Inhibition and downregulation of Bcl-2 and Bcl-xL result in the initiation of the intrinsic or mitochondrial pathway of apoptosis by influencing mitochondrial membrane permeabilization and subsequent activation of the apoptosome, caspase 9, and effector caspases 3 and 7. Stimulation of the AR by DHT rescues VCaP prostate cancer cells from AT-101-mediated apoptotic cell death by inhibition of caspase activation, with the exception of caspase 3 (Fig. 1B,C). AR activation also protects Bcl-xL from complete degradation (Fig. 2), a result consistent with previously reported findings that $\mathrm{Bcl}-\mathrm{xL}$ expression can be regulated by an AR-dependant mechanism [Sun et al., 2008]. Persistent, albeit low, levels of this pro-survival Bcl-2 family member may be partially responsible for the increased survival of androgenstimulated prostate cancer cells. Therefore, AR activation mediates the inhibition of caspase activation by rescuing $\mathrm{Bcl}-\mathrm{xL}$ expression. In addition to Bcl-xL, phospho-AKT may also be involved in androgen-mediated suppression of apoptosis.

Interestingly, VCaP cells treated with bicalutamide, or ADT, show no significant difference in apoptosis from the control or DHT-treated cells. ADT was also insufficient to activate the caspase cascade (Fig. 4) and resulted in an increase in the expression of survival proteins Bcl-2 and surviving (Fig. 5A). This suggests the presence of a survival response by androgen-deprived prostate cancer cells that must be overcome for therapeutic apoptosis to transpire.

In the presence of AR activation an increase in the expression level of XIAP, AKT, and phospho-AKT ser473 was seen during
AT-101 treatment in comparison to AT-101 alone and combination of AT-101/bicalutamide treatment groups (Fig. 5). XIAP is a member of a family of inhibitors of apoptosis responsible for controlling apoptosis by inhibiting of caspase activation. The expression of prosurvival proteins, in addition to the presence of AKT activation, maybe responsible for increasing VCaP cancer cell survival in vitro. Thus, AR activation by DHT undermines the apoptotic effects of AT101. However, when bicalutamide is used in combination with AT101 in the presence of AR activation, apoptosis increases (Fig. 3B), which is consistent with the increased levels of caspase activation (Fig. 4). In addition, combination therapy overcomes the survival response by reducing the expression levels of survival proteins: Bcl$\mathrm{xL}$, survivin, XIAP, and AKT, thus allowing the cells to activate the caspase cascade resulting in apoptosis of the cancer cells. The presence of activated AKT, phospho-AKT ser 473 was not altered by the bicalutamide and AT-101 combination (Fig. 5).

In conclusion, these data indicate that the use of AT-101 or ADT as monotherapies may not be sufficient to significantly change growth kinetics and induce apoptosis in androgen-sensitive prostate cancer cells. However, the combination of these two therapies demonstrates a synergistic effect by reducing the expression of prosurvival proteins while mediating the activation of the caspase cascade (Fig. 6). Recently, AT-101 as a single agent was studied in a Phase I/II clinical trial in men with AI prostate cancer; the results indicated only a modest response by PSA monitoring. However, a Phase II clinical trial is being conducted to test the efficacy of AT101 in combination with ADT [Liu et al., 2009]. Additional studies 


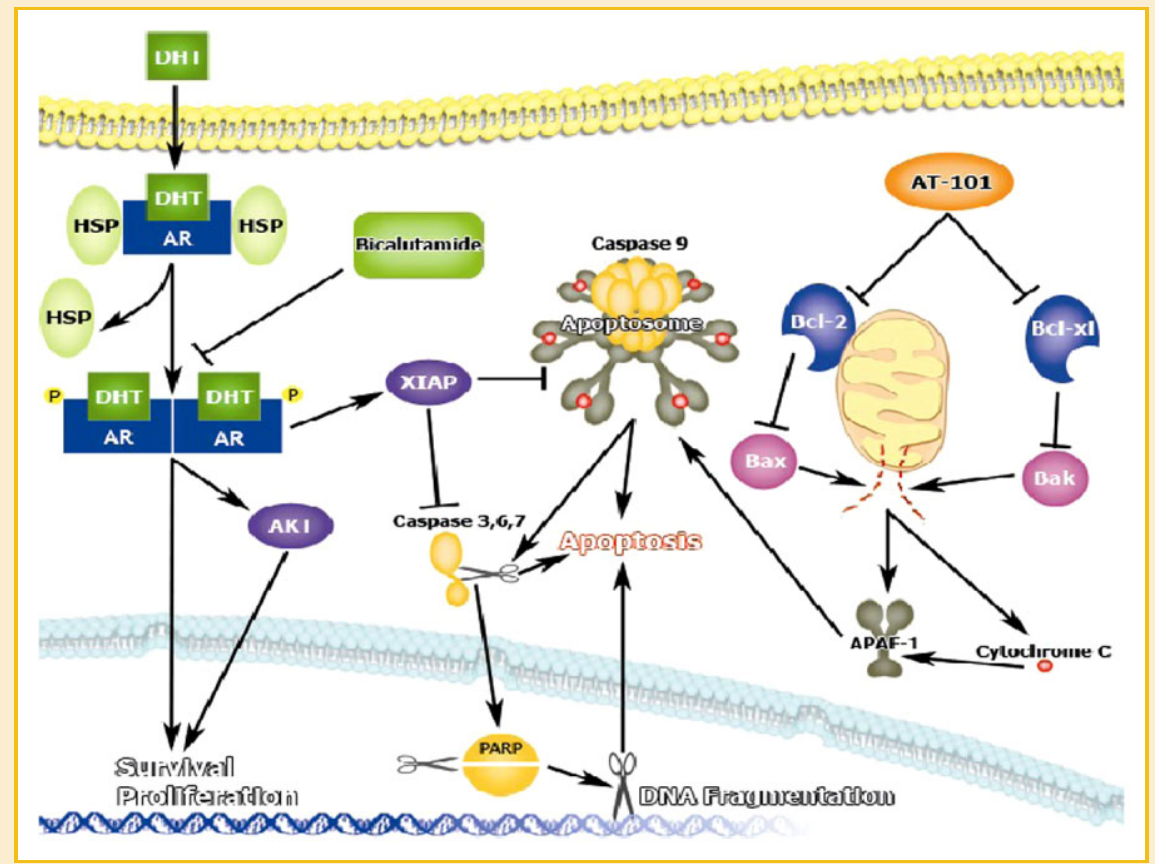

Fig. 6. Actions of AT-101, bicalutamide, and AR activation on cell survival and intrinsic apoptosis. AT-101 mimics pro-apoptosis of BH-3 only proteins inhibiting pro-survival proteins $\mathrm{Bcl}-2$ and $\mathrm{Bcl}-\mathrm{xL}$. Pro-survival Bcl-2 family members inhibit pro-apoptosis proteins Bax and Bak. Effectors Bax and Bak induce mitochondrial membrane permeabilization resulting in the release of cytochrome $c$. Cytochrome $c$ associates with Apaf- 1 and caspase- 9 forming the apoptosome. Caspase- 9 then activates caspases 3,6 , and 7 resulting in the cleavage of PARP and other substrates resulting in apoptosis. Activation of AR by dihydrotestosterone (DHT) increases the expression of AKT and XIAP leading to survival and proliferation. XIAP can directly inhibit apoptosis by inhibition of caspase activation. Bicalutamide inhibits AR activation, thus inhibiting the ability of AR to increase survival and proliferation.

are needed to determine the mechanism of AT-101-mediated downregulation of Bcl-2 family proteins and the significance of caspase 3 activation when AT-101 is used in the presence of AR activation. Further examination of the efficacy of using AKT inhibitors in conjunction with AT-101 and ADT to elicit therapeutic responses may also be warranted.

\section{REFERENCES}

Chipuk JE, Green DR. 2008. How do BCL-2 proteins induce mitochondrial outer membrane permeabilization? Trends Cell Biol 18:157-164.

Cory S, Adams JM. 2002. The Bcl2 family: Regulators of the cellular life-ordeath switch. Nat Rev Cancer 2:647-656.

Eder IE, Culig Z, Putz T, Nessler-Menardi C, Bartsch G, Klocker H. 2001. Molecular biology of the androgen receptor: From molecular understanding to the clinic. Eur Urol 40:241-251.

Frenzel A, Grespi F, Chmelewskij W, Villunger A. 2009. Bcl2 family proteins in carcinogenesis and the treatment of cancer. Apoptosis 14:584-596.

Fujimoto N, Chang C, Nomura M, Matsumoto T. 2005. Can we prevent prostate cancer? Rationale and current status of prostate cancer chemoprevention. Urol Int 74:289-297.

Heinlein CA, Chang C. 2004. Androgen receptor in prostate cancer. Endocr Rev 25:276-308.

Hockenbery D, Nunez G, Milliman C, Schreiber RD, Korsmeyer SJ. 1990. Bcl2 is an inner mitochondrial membrane protein that blocks programmed cell death. Nature 348:334-336.

Huang X, Zhang X, Farahvash B, Olumi AF. 2007. Novel targeted proapoptotic agents for the treatment of prostate cancer. J Urol 178:1846-1854.
Huggins C, Hodges CV. 1941. Studies on prostatic cancer II: the effects of castration on advanced carcinoma of the prostate gland. Arch Surg 43:209-223.

Jemal A, Siegel R, Ward E, Hao Y, Xu J, Thun MJ. 2009. Cancer statistics, 2009. CA Cancer J Clin 59:225-249.

Kline MP, Rajkumar SV, Timm MM, Kimlinger TK, Haug JL, Lust JA, Greipp PR, Kumar S. 2008. R-(-)-gossypol (AT-101) activates programmed cell death in multiple myeloma cells. Exp Hematol 36:568-576.

Korenchuk S, Lehr JE, MClean L, Lee YG, Whitney S, Vessella R, Lin DL, Pienta KJ. 2001. VCaP, a cell-based model system of human prostate cancer. In Vivo 15:163-168.

Liu G, Kelly WK, Wilding G, Leopold L, Brill K, Somer B. 2009. An open-label, multicenter, phase I/II study of single-agent AT-101 in men with castrateresistant prostate cancer. Clin Cancer Res 15:3172-3176.

Loberg RD, St John LN, Day LL, Neeley CK, Pienta KJ. 2006. Development of the $\mathrm{VCaP}$ androgen-independent model of prostate cancer. Urol Oncol 24:161-168.

Loberg RD, McGregor N, Ying C, Sargent E, Pienta KJ. 2007. In vivo evaluation of AT-101 (R-(-)-gossypol acetic acid) in androgen-independent growth of VCaP prostate cancer cells in combination with surgical castration. Neoplasia 9:1030-1037.

Ma WW, Adjei AA. 2009. Novel agents on the horizon for cancer therapy. CA Cancer J Clin 59:111-137.

Macoska JA, Adsule S, Tantivejkul K, Wang S, Pienta KJ, Lee CT. 2008. $(-)$ Gossypol promotes the apoptosis of bladder cancer cells in vitro. Pharmacol Res 58:323-331.

Marzo I, Naval J. 2008. Bcl-2 family members as molecular targets in cancer therapy. Biochem Pharmacol 76:939-946.

Meng Y, Tang W, Dai Y, Wu X, Liu M, Ji Q, Ji M, Pienta K, Lawrence T, Xu L. 2008. Natural BH3 mimetic (-)-gossypol chemosensitizes human prostate 
cancer via Bcl-xL inhibition accompanied by increase of Puma and Noxa. Mol Cancer Ther 7:2192-2202.

Miyamoto H, Messing EM, Chang C. 2004. Androgen deprivation therapy for prostate cancer: Current status and future prospects. Prostate 61:332-353.

Pegoraro L, Palumbo A, Erikson J, Falda M, Giovanazzo B, Emanuel BS, Rovera G, Nowell PC, Croce CM. 1984. A 14;18 and an 8;14 chromosome translocation in a cell line derived from an acute B-cell leukemia. Proc Natl Acad Sci USA 81:7166-7170.

Perlmutter MA, Lepor H. 2007. Androgen deprivation therapy in the treatment of advanced prostate cancer. Rev Urol 9(Suppl 1): S3-S8.

Petros AM, Olejniczak ET, Fesik SW. 2004. Structural biology of the Bcl-2 family of proteins. Biochim Biophys Acta 1644:83-94.

Pienta KJ, Bradley D. 2006. Mechanisms underlying the development of androgen-independent prostate cancer. Clin Cancer Res 12:1665-1671.

Sun A, Tang J, Hong Y, Song J, Terranova PF, Thrasher JB, Svojanovsky S, Wang HG, Li B. 2008. Androgen receptor-dependent regulation of $\mathrm{Bcl}-\mathrm{xL}$ expression: Implication in prostate cancer progression. Prostate 68:453-461.

Taichman RS, Loberg RD, Mehra R, Pienta KJ. 2007. The evolving biology and treatment of prostate cancer. J Clin Invest 117:2351-2361.
Tsujimoto Y, Finger LR, Yunis J, Nowell PC, Croce CM. 1984. Cloning of the chromosome breakpoint of neoplastic B cells with the $t(14 ; 18)$ chromosome translocation. Science 226:1097-1099.

van Bokhoven A, Varella-Garcia M, Korch C, Johannes WU, Smith EE, Miller HL, Nordeen SK, Miller GJ, Lucia MS. 2003. Molecular characterization of human prostate carcinoma cell lines. Prostate 57:205-225.

Walczak JR, Carducci MA. 2007. Prostate cancer: A practical approach to current management of recurrent disease. Mayo Clin Proc 82:243249.

Wang G, Nikolovska-Coleska Z, Yang CY, Wang R, Tang G, Guo J, Shangary S, Qiu S, Gao W, Yang D, Meagher J, Stuckey J, Krajewski K, Jiang S, Roller PP, Abaan HO, Tomita Y, Wang S. 2006. Structure-based design of potent small-molecule inhibitors of anti-apoptotic Bcl-2 proteins. J Med Chem 49:6139-6142.

Youle RJ, Strasser A. 2008. The BCL-2 protein family: Opposing activities that mediate cell death. Nat Rev Mol Cell Biol 9:47-59.

Zhang M, Liu H, Tian Z, Griffith BN, Ji M, Li QQ. 2007. Gossypol induces apoptosis in human PC-3 prostate cancer cells by modulating caspasedependent and caspase-independent cell death pathways. Life Sci 80:767774. 